\title{
MALAYSIAN CHINESE NEW YEAR DISHES NOMENCLATURE
}

\author{
Ng Man Ling', Ang Lay Hoon ${ }^{1}$, Lam Kai Chee ${ }^{2}$ \\ ${ }^{1}$ Universiti Putra Malaysia and ${ }^{2}$ Universiti Malaysia Sarawak
}

\begin{abstract}
The Chinese people are generally very particular in the naming of the dishes served at restaurants. For the Chinese, dish naming is a knowledge involving the combination of the dishes' ingredients together with their names to ensure that the names given can fit the specialty of the dishes and also maintain their uniqueness at the same time. This paper explains the nomenclature of Malaysian Chinese New Year dishes and investigates the impact the Chinese culture has on it. Malaysian Chinese dishes are normally named based on three methods, which consider the ingredients used (Realistic Nomenclature), cultural implication (Impressionistic Nomenclature), or a combination of both (The Actual Situation Nomenclature). A literature review revealed that a majority of the Malaysian restaurants tend to name the dishes by highlighting the cultural implication of the dishes. In this study, a total of 295 dishes were collected from 24 restaurants to classify the name of the dishes according to the three methods. The analysis revealed that dishes nomenclature in Malaysia is complex. Most of the Chinese New Year dishes are named according to cultural implication because Chinese people believe that a given good name will affect the year's fortune.
\end{abstract}

Keywords: MALAYSIAN, CHINESE MALAYSIAN, CHINESE RESTAURANTS, DISH NAMING, CHINESE CULTURE

\section{Introduction}

The list of basic human needs includes clothes, food, housing and transportation. Among the four, people need food the most. For the Chinese people, food is the most important element, not only for survival but also to showcase their culture. Food culture is always prominent in major events such as weddings, funerals, grand openings and for building relationships, whether professionally as in business relationships or in personal relationships. This shows that "eating" plays a major part in our lives. (Wu, 2008, p.237)

As the standard of living improves, people are not only particular about the food quantity, quality and nutrition, but they also have a certain expectation on taste of food, ingredients used and dining environment. In the culinary culture, diners will normally be presented with a menu of dishes to order.

The name of a dish will help convey the message of food presentation, reflecting the wisdom of Chinese people and their culinary skills. (Yu \& Huai, 2011, p.3). In addition, a dish with a "good" name will psychologically improve the diner's experience of the dish and as a result, enhances the restaurant's reputation. Therefore, the nomenclature of dishes is important.

Today, there are plenty of restaurants and catering services competing with each other. In order for them to thrive in their businesses, they have to be innovative in creating new dishes, by using new 


\section{MALAYSIAN CHINESE NEW YEAR DISHES NOMENCLATURE}

ingredients, new culinary methods and giving the dishes attractive names, so that they can attract more customers.

Compared to the other ethnic or Western dishes, there are not only various culinary arts in Chinese cuisine but the name of a particular dish also possesses Chinese characteristics in it. This is supported by Chen Jin Biao (2001, p.13), who stated that the naming of dishes, along with the Chinese culinary history, plays a special role in the food culture development. Meanwhile, Xie Qiong (2007, p.747) also recorded that the process of naming dishes involves the elements of physical world, linguistic world and social psychology world complementing each other.

The culinary culture reflected by the name of a dish has become an important part in the social culture. From the words and symbols used in the language to name a dish, especially the signature dish, not only does it reflect the prestige of the restaurant (Zhou, 2000, p.34), it also reflects the cultural characteristics of the certain district that it belongs to (Zhong, 2006, p.79).

The Chinese from mainland China, as well as overseas Chinese, are very particular about "eating". The objective of this article is to study the culture of naming Chinese New Year dishes among the Chinese Malaysians.

\section{Literature Review}

Chinese people are very particular about dish naming, hence there are many Chinese scholars who do research it. As Zhen Song Hui (2005, p.69) asserted, a good and well prepared dish will make people happy, increase their appetite and such experience will be shared widely by good comments and vice versa.

In 2002, Zhu Xi Xiang (2002, p.56) conducted a study on the popularity of Chinese dishes. In his study, he reported that the names of Chinese dishes were generally based on the food ingredients used and also cuisine cooking techniques. He also reported that this was how most of the dishes in China were named. According to him, foods in China were named more elegantly because the names of dishes there were derived with reference from historical literatures and texts, and traditions, with great emphasis in their presentation. Deng Zhi Feng (2007, p.169) had summarized that there were 1596 dishes names in”中国饮食大辞典・菜肴类” [ zhong guo yin shi da chi dian • cai yao lei ${ }^{1}$ (Chinese Diet Dictionary $\bullet$ vegetable category ${ }^{2}$ ). He found out that nearly $55 \%$ of 876 names of the dishes studied were formed in four characters and is the most common structure of Chinese idioms.

There are many varieties of dishes nomenclature. Guo Yan $(2008$, p.72) categorized the names of the dishes into 10 categories according to the composition of food ingredients, cuisine cooking methods, uniqueness in taste, symbolic representation of the dishes, origin of dishes, mascot, homophonic, floral, historical anecdote and legends, and lastly the spontaneous naming by the consumer after consumption.

According to Wei Qi Zhou (2009, p.8), both general dishes and fancy dishes were given names usually before or after the dishes were developed. A general dish nomenclature was given based on its cooking methods with main ingredients used, seasoning methods of the main ingredients, cooking methods with the uniqueness of the ingredients used, main ingredients with the uniqueness of complimenting

\footnotetext{
${ }^{1}$ All the pronunciation of the Chinese characters in this paper are in Italic.

${ }^{2}$ All translation of the Chinese characters in this paper are literal translation (i.e. not the original

English name of the Chinese character, if they had any) unless indicated otherwise.
} 


\section{MALAYSIAN CHINESE NEW YEAR DISHES NOMENCLATURE}

ingredients and complimenting ingredients with cooking methods used. However, fancy dish nomenclature was only given according to their "colour", "taste", "form" and "actual ingredients used".

Chinese New Year is the biggest celebration for Chinese people, so there are many activities to be carried out. People believe that the blessings and happiness that this festival brings will then flow throughout the New Year.

In the past, Chinese New Year was regarded as the Beginning of Spring in the 24 solar terms known as “立春” [li chun] which means the beginning of a brand new year. Today, Chinese New Year is referred to as the First Day of Lunar Calendar “农历正月初一” [ nong li zheng yue chu yi]. The Chinese New Year dishes play an important role in both, the Chinese festive seasons and during wedding events. People are concerned about the literal meaning of the names besides the high quality in terms of colour, aroma and taste of the dishes. Therefore, the dishes must be given names with auspicious words for good omen, so naturally they are very concerned about the dishes names, presenting them with extra elegance and with good meanings. Additionally, Guo Yan $(2008$, p.72) stated that, a dish with a good name should enable the customer to visualise the dish together with its method of presentation and have an appetizing "feeling". Chinese people like to say auspicious words as blessing to other people and they even use auspicious words for dish names as they reflect the Chinese living concept and auspicious wishes (Liu, 2002, p.35). Qu Dian Kui's (1994, p53) research revealed that dish naming might be based on numeric, places, names, animals, colours, floral, minerals or idioms.

Liu Feng Ling (2005, p.424-425) classified dish names based on the ingredients used and its cultural implication. Cultural implication's nomenclature means using thought association, metaphor, symbolism, exaggeration, euphony and rhetoric to create dish names. Meanwhile, Cultural Implication's nomenclature does not use food ingredients and cuisine cooking methods to name the dish; instead using a nice name which rhymes, encompassing customers' psychology. This was supported by Xie Qiong (2007, p.747) who discovered that this kind of nomenclature could directly reflect the properties of the dishes besides enhancing the dish's artistic appearance to increase customers' appetite.

On the other hand, Chen Jin Biao (2001, p.14) asserted that certain dish names reflect the characteristic of the dishes taking the names when they were first introduced to the customers. He also categorised dish nomenclature into 2 major types, which are Realistic Nomenclature and Impressionistic Nomenclature.

Chen Jin Biao classified the Realistic Nomenclature by the cooking ingredients, food attributes, cooking methods and also commemorative aspects which were the elements in the dishes. The example of such elements are as the following: the ingredients of the dishes and their seasoning are the elements of cooking ingredients; colour, taste, shape, and holding container are the elements of food attributes; process and cooking method are the elements of cooking methods; names of people and places are the elements of commemorative aspects. Furthermore, he classified the Impressionistic Nomenclature by their references to auspicious and good names, for example cultural allusions, idioms and verses.

However, Chen Jin Biao (2001, p.14) also proposed a third category, which is the Actual Situation Nomenclature, or naming the dishes based on the enhancement and modification of a certain dish characteristics. This kind of nomenclature is formed by the association of both real and illusion structures. Through the names, it allows the consumers to know the ingredients used and their implicit elegance with the combination of reality and allusion nomenclature for the names of the dishes. Chen Jin Biao had also stated some of the common vocabulary used by the chef such as colour representation, shape representation and numeric representation. The words normally used in colour representation 


\section{MALAYSIAN CHINESE NEW YEAR DISHES NOMENCLATURE}

were 翡翠 [ fei cui] (jade) to represent green, 白玉 [bai yu] (white jade) to represent white, 珊瑚 [shan $h u]$ (coral) to represent red and 水晶 [shui jing] (crystal) to represent something transparent.

For the shape representation, there are three sub-categories, namely, animals, plants and utensils. The words that are used in animals' category are 金鱼 [jin yu] (golden fish), 蝴蝶 [hu die] (butterfly), 松 鼠 [song shu] (squirrel); the words used in plants category are 芒果 [mang guo] (mango), 西瓜 [xi gua] (watermelon), 荷花 [he hua] (lotus) and 萝卜 [luo bo] (radish); the words used in utensils category are 荷包 [he bao] (small purse), 珍珠 [zhen zhu] (pearl), 椰壳 [ye ke] (coconut husk), 玻璃 [bo li] (glass) etc. The numerics normally used in ingredient representation are 一品 [yi pin] ('first rate') to represent that was a first rated dish, 二度 [erdu] ('second degree') to represent second, 三鲜 [san xian] ('three delicacies') to represent three seafood or a fresh dish and 四宝 [si bao] ('four treasure') to represent four types of different ingredients in a dish.

The food culture of a country can reflect the historical, economic, and cultural development of the ethnic locals. Zhong An Ni (2006, p.79) discovered that dish names based on names of people or places could reflect the traditional characteristics of the dishes. Names of famous local celebrities are used to create a good impression. Zhang Hui Lian (2009, p.364) had reported that one could understand the culture of the local by simply understanding the names of the dishes because they reflect different traditional cultures and customs. Malaysian Chinese food culture is basically inherited from the tradition of Chinese culture; hence, one must understand Chinese dishes nomenclature before studying Malaysian Chinese food culture.

\section{Methodology}

Malaysia is a multi-racial country with the Chinese making up a quarter of the population thus retaining the characteristics of Chinese. This survey was to study the Malaysian Chinese cultural psychology from the perspective of sociolinguistics through the Chinese food naming phenomenon. The discussed targets were acquired from the local publishers of Chinese New Year cuisine magazines or articles within the downtown of Selangor and Kuala Lumpur, Malaysia (also known as "Klang Valley"). These included a total of 24 restaurants namely 金香阁 [Jin Xiang Ge] ('golden fragrant pavilion'), 海外天 大饭店 [Hai Wai Tian Da Fan Dian] (Restaurant oversea), 皇廷滋味馆[Huang Ting Zi Wei Guan] (Restaurant Crown Palace), 聚满轩[Ju Man Xuan] (Restaoran Jui Moon Heen), 喜来登翡翠大酒家 [Xi Lai Deng Fei Chui Da Jiu Jia] (Hee Lai Ton Restaurant), 阿顺哥鱼翅 [A Shun Ge Yu Chi] (Chef Soon Koh Restaurant Sdn Bhd), 翠恒酒家 [Chui Heng Jiu Jia] (Chuai Heng Restaurant), 古月天酒楼 [Gu Yue Tian Jiu Lou] (Gu Yue Tian Restaurant), 珍宝饮食业集团 [Zhen Bao Yin Shi Ye Ji Tuan] (Janbo Group of Restaurant), 客家饭店[Ke Jia Fan Dian] (Hakka Restaurant), 喜来登翡翠（锡米山） 海鲜大酒家 $[X i$ Lai Deng Fei Chui (Xi Mi Shan) Hai Xian Da Jiu Jia] (Sheraton Emerald (Simi Hill) Seafood Restaurant) and 皇宫海鲜酒家 [Huang Gong Hai Xian Jiu Jia] (Palace Group Restaurant).

A total of 295 Chinese New Year Dishes names were obtained for the study. This article defined the dishes according to the ingredients used (Realistic Nomenclature), its cultural implication (Impressionistic Nomenclature), or a combination of both (The Actual Situation Nomenclature) and interpreted together with their structure and content so as to facilitate the understanding of the Malaysian Chinese sociolinguistic phenomenon and to discover their thoughts and culture.

Based on the dishes nomenclature proposed by Chen Jin Biao (2001) and Liu Feng Ling (2005), a model of dishes nomenclature is adapted for this study shown in Table 1 below: 


\section{MALAYSIAN CHINESE NEW YEAR DISHES NOMENCLATURE}

Table 1: Classification of dish naming

\begin{tabular}{|l|l|l|}
\hline \multicolumn{1}{|c|}{ Nomenclature } & \multicolumn{1}{|c|}{ Element in Nomenclature } & \multicolumn{1}{c|}{ Examples of Element } \\
\hline \multirow{3}{*}{ Realistic Nomenclature } & Cooking ingredients & Ingredients \\
\cline { 2 - 3 } & Food attributes & Colour, taste, appearance, vessel. \\
\cline { 2 - 3 } & Cooking methods & Process, cooking method \\
\cline { 2 - 3 } & Commemorative aspects & People names, place name. \\
\hline Impressionistic Nomenclature & Good name & $\begin{array}{l}\text { Allusion, proverbs, good values, } \\
\text { mascot, mineral, numeric, } \\
\text { homonym. }\end{array}$ \\
\hline $\begin{array}{l}\text { The Actual Situation } \\
\text { Nomenclature }\end{array}$ & $\begin{array}{l}\text { Combination of the element in Realistic Nomenclature and } \\
\text { Impressionistic Nomenclature. }\end{array}$ \\
\hline
\end{tabular}

\section{Results}

A total of 295 names of Chinese New Year Dishes were analysed according to the ingredients used (Realistic Nomenclature), its cultural implication (Impressionistic Nomenclature), or a combination of both (The Actual Situation Nomenclature) and these were interpreted together with their structure and content.

Table 2: Statistics of 295 Chinese New Year Dishes with their Nomenclature

\begin{tabular}{|l|l|c|c|}
\hline & \multicolumn{1}{|c|}{ Nomenclature } & Quantity & Percentage \\
\hline 1. & Ingredients & 121 & $41.02 \%$ \\
\hline 2. & Colour & 42 & $14.28 \%$ \\
\hline 3. & Taste & 15 & $5.08 \%$ \\
\hline 4. & Appearance & 13 & $4.41 \%$ \\
\hline 5. & Vessel & 4 & $1.36 \%$ \\
\hline 6. & Process & 4 & $1.36 \%$ \\
\hline 7. & People Names & 2 & $0.68 \%$ \\
\hline 8. & Place Names & 19 & $6.44 \%$ \\
\hline 9. & Cooking Methods & 64 & $21.69 \%$ \\
\hline 10. & Allusions & 1 & $0.34 \%$ \\
\hline 11. & Proverbs & 91 & $30.85 \%$ \\
\hline 12. & Good Values & 160 & $54.24 \%$ \\
\hline 13. & Mascot & 19 & $6.44 \%$ \\
\hline 14. & Mineral & 24 & $8.14 \%$ \\
\hline 15. & Numeric & 25 & $8.47 \%$ \\
\hline 16. & Homonym & 13 & $4.41 \%$ \\
\hline
\end{tabular}

Table 2 shows the 16 main nomenclatures used in festive dishes with most of them practicing the good values nomenclature, which accounts for $54.24 \%$. This data shows that Chinese people are very particular about prosperity, auspicious wordings and also how the chefs give their blessings through the special and meaningful dishes' names.

The specialty of Chinese New Year dishes is that some of them are named based on rhyme and rhythm, being matched to represent great blessing. For example “发菜” [ fa cai] (black moss) with “发财” [ $f a$ cai] (prosperity) are both pronounced as " $\mathrm{Fa}$ Cai" with the latter word bringing the good wishes to the people. However, this type of nomenclature is seldom found in Chinese wedding dishes as this clearly 


\section{MALAYSIAN CHINESE NEW YEAR DISHES NOMENCLATURE}

indicates that homonym nomenclature is applied to fulfil the consumer's needs and the purpose of the occasion.

\section{Realistic Nomenclature of Chinese New Year dishes}

This Chinese New Year dishes nomenclature is mainly formed by the physical representation of the actual dish itself. As such, from the physical appearance of the dish, people will be able to make out the main ingredients used, method of cooking, place of origin and its taste. In this study, we found out that the Chinese New Year dishes nomenclature is based on one to four combinations of nomenclatures.

For the single nomenclature, the dishes are named based solely on the ingredients, especially the main ingredient, such as 参须海底椰 [shen xu hai di ye] ('ginseng rootlets with sea coconut'), 龟苓膏海底 椰 [gui ling gao hai di ye] ('guiling jelly with sea coconut'), 鲍贝雪梨鱼生 [bao bei xue li yu sheng] ('abalone snow pear yee shang') and so on.

Dish name derived from a combination of two nomenclatures are a combination of cooking ingredients with the cooking method, as in 妈蜜汁焗螃蟹 [ ma mi zhi ju pang xie] ('marmite baked crab'), so people will know how the dish is cooked based on its name. Other types of two nomenclature dish names are a combination of ingredients with the vessel, as in 香芋鱼头煲 [xiang yu yu tou bao] ('taro fish head pot'); a combination of ingredients with the name of a place, as in 澳洲鲍鱼鱼生 [ao zhou bao yu yu sheng] ('Australia abalone yeeshang'); combination of ingredients with taste, as in 咸猪手 [xian zhu shou] ('salty pig front leg'), 麻辣鸡 [ma la ji] ('hot and spicy chicken'); combination of ingredients with appearance as in 和牛蔬菜卷 [he niu shu cai juan] ('wagyu vegetable roll'), 肉碎马 铃薯粒水豆腐 [rou sui ma ling shu shui dou fu] ('minced meat with potatoes and soft bean curd') in which people will know the appearance of the dish will have its ingredients minced and cooked with bean curd.

A total of 4 combinations are available for Realistic Nomenclature, each consisting of 3 elements. Firstly, a combination of cooking ingredients, appearance, and the cooking method, as in 海鲜芦笋拼 鱼卷 [hai xian lu xun ping yu juan] ('seafood with asparagus and fish roll'), 牛膝圆肉卷炒蔬菜与金 针菇 [niu xi yuan rou juan chao shu cai yu jin zhen gu] ('beef knuckle roll with fried vegetable and mushroom') from which people will know the dish's appearance is in a "roll" shape and the cooking method is by "frying". Secondly, a combination of ingredients, place name with cooking method as in 港式当归芝麻烧鸭 [gang shi dang gui zhi ma shao ya] ('Hong Kong style sesame roasts duck with Chinese angelica'), in which people will know the origin of the dish is from Hong Kong and "roasting" being the cooking method; 加州鳕鱼蒸糯米 [jia zhou xue yu zheng nuo mi] ('California cod fish steamed with glutinous rice') - in which the name of the place is "California" and cooking method is by “steaming”. Thirdly, a combination of ingredients, place name with the taste as in 四川香辣虾 [Sze Chuan xiang la xia] ('Sze Chuan style spicy shrimp'). People will know this dish taste and its place of origin by its name. And lastly, the combination of ingredients, taste with cooking method as in 甜菜蒸 桂花鱼 [tian cai zheng gui hua yu] ('sweat vegetable steamed Mandarin fish') - a dish with sweet taste and cooked by steaming.

Dish names derived from a combination of four nomenclatures are a combination of ingredients, taste, and the name of place and the cooking method of the dish. For example, 甜菜蒸澳洲七星斑 [tian cai zheng ao zhou qi xing ban] ('steam Australia leopard coral grouper with sweet vegetable') people will 


\section{MALAYSIAN CHINESE NEW YEAR DISHES NOMENCLATURE}

know that the taste of this dish is sweet, the name of the place is Australia, cooking method is by steaming and the main ingredients of dish are vegetables and leopard coral grouper. The same goes for 甜菜蒸本地斗鲳鱼 [tian cai zheng ben di dou chang yu] ('steam local butterfish with sweet vegetable') we will know the taste, origin of dish, cooking method and the ingredients of food through the dish's name.

The Chinese New Year dishes that were mainly formed by Ingredient Nomenclature would include ingredients, cooking methods, cooking process, vessel, a name referencing to a place and appearance. Those Chinese New Year dishes which are named according to people's name cannot be categorized under Realistic Nomenclature because the given name does not give any clue or indication of the ingredients used. For example, 佛磪涎 [fo cui xian] ('Buddha precipitous saliva') has included the name of the Buddha as the name of the dish. The name of this particular dish does not allow us to guess the ingredients used. This type of fancy name might not bring about eventual understanding about the dish, but it may make the consumers to become curious and attract them towards giving the dish a try.

\section{Impressionistic Nomenclature of Chinese New Year dishes}

In previous studies (Zhu Xi Xiang, 2002; Chen Jin Biao, 2001; Liu Feng Ling, 2005), Impressionistic Nomenclature can be divided into four categories, namely allusions, proverbs, good values and homonym. Chinese people are very particular about things being auspicious with good meaning, especially in special celebrations; hence the chef will use this kind of nomenclature in naming their dishes. Some of the examples of the nomenclatures which include proverbs with auspicious meaning are 财源广进 [cai yuan guang jin] ('money and treasure will be plentiful'); some dishes portray good values as in, 幸福团圆 [xin fu tuan yuan] ('blessed reunion'), 盆满笑开颜 [peng man xiao kai yan] ('pots full of joy and laughter'), 年丰财源广 [nian feng cai yuan guang] ('plentiful harvests in succession and abundance in wealth'). Lastly, some dish names are allusion based, as in 福州驰名佛 跳墙 [Fu Zhou chi ming fo tiao qiang] ('Fuzhou Buddha jumps over the wall'). This nomenclature does not name the ingredients directly and clearly in their name. All these dish names do not indicate the ingredient used but seem to bring about positive outcomes.

Some of the chefs deliberately select the word 金鸡报喜 [jin ji bao xi] ('rooster annunciation') as their dish name to make the dish sound more elegant and to attract customer's attention; and 生生不息 [sheng sheng bu xi] ('continuous reproduction breed endlessly') was named from the homonym of the main ingredient, the sea cucumber which is pronounced as 参 [shen] in Cantonese. Using the same concept, 喜哈大笑 [xi ha da xiao] ('laugh heartily') was created using the pronunciation of the prawn which is the main ingredient in the dish, in Cantonese that sounds like 哈 [ha] (laughing) to represent a cheerful New Year. Chinese people's hope for prosperity have inspired chefs to name 发菜 [fa cai] (black moss) as 发财 [ fa cai] (to get rich) leading to the creation of the name 包你发财 [bao ni fa cai] ('your wealth is guaranteed'), 发财好市 [fa cai hao shi] ('get rich with booming market') instead of 发菜蚝豉柱甫 [fa cai hao chi zhu fu] ('black moss, dried oyster with conpoy’) at renowned Cantonese cuisine restaurants.

\section{The Actual Situation Nomenclature of Chinese New Year dishes}

The Actual Situation Nomenclature incorporates both Realistic Nomenclature and Impressionistic Nomenclature in the name of dishes. When the diners see the name of the dishes, they will know the raw materials used for the dishes, which is at times, elegantly named. In this study, we found out that this dishes nomenclature is based on two to four combinations of nomenclatures. 


\section{MALAYSIAN CHINESE NEW YEAR DISHES NOMENCLATURE}

For the combination of 2 nomenclatures, the popular elements used are colour, ingredients, numerical reference and good meaning. For example, 荷叶黄金饭 [he ye huang jin fan] ('golden rice in lotus leaf') is a combination of colour and ingredients; 菜香三宝菜园鸡 [cai xiang san bao cai yuan ji] ('village chicken with aromatic vegetable and three treasures), 四宝萝卜糕 [si bao luo bo gao] ('four treasure turnip cake') are a combination of numeric and ingredients and the 吉利鱼鳔 [ji li yu biao] ('lucky fish maw') is a combination of good meaning and ingredients.

In the combination of 3 nomenclatures, the popular elements used are colour, ingredients, cooking method, good value and process. For example, 红烧素鱼鳔 [hong shao su yu biao] ('red braising vegetarian fish maw'), 红烧海味烩鲍翅 [hong shao hai wei hui bao chi] ('red braising seafood braise abalone') which are formed by colour, cooking method and the ingredients. 金瓜福寿饭 [jin gua fu shou fan] ('golden pumpkin with happiness and longevity rice') formed by colour, good value and the ingredients, giving the first impression to the diners that this dish is golden in colour and it will bring them happiness and longevity. 鸿图烧鸭 [hong tu shao ya] ('grand prospect roast duck'), 吉利烧鸡 [ji li shao ji] ('lucky roast chicken'), 富贵卤鸭 [fu gui ru ya] ('wealthy and prestigious stewed duck') are the nomenclatures that are formed by good value, cooking method and the ingredients. Besides 富 贵鱼片 [fu gui yu pian] ('wealthy and prestigious fish fillet') is the nomenclatures formed by good values, process and the ingredients.

In the combination of 4 nomenclatures, the popular elements used are colour, appearance, ingredients, cooking method, numerical reference and name of place. For example, 白花煎虾饼 [ bai hua jian xia bing] ('fried prawn cracker with white flower'), 豆浆银鱼仔炒蛇豆 [dou jiang yin yu zai chao she dou] ('stir fried snack bean with soya bean and small silver fish') are the nomenclatures formed by colour, appearance, cooking method and the ingredients. 金片双椒炒花菇 [jin pian shuang jiao chao hua gu] ('stir fried mushroom with golden flakes and double chili') is the nomenclature formed by numeric, colour, cooking method and the ingredients. Lastly, 福州双宝烩鲍翅 [Fu Zhou shuang bao hui bao chi] ('Fu Zhou stewed abalone with double treasures') is the nomenclature formed by the name of place, numeric, cooking method and the ingredients.

Among the three major types of nomenclatures, the Actual Situation Nomenclature (combination of ingredients used and cultural implication) is more preferable to be used in Chinese New Year dish naming process because it reflects meanings represented by the dish. Besides, the consumers would be able to deduce the ingredient used through the dish's name. Conversely, dish names with Cultural Implication (Impressionistic Nomenclature) cause lots of confusion for the consumers when they order food because the name doesn't clearly show or reflect the ingredients used.

\section{Discussion}

The ancestors of Malaysian Chinese emigrated from China to Malaysia over hundreds of years ago but the cultural heritage of the Chinese is still being carried on by their next of kin and passed on to their grandchildren from generation to generation. This cultural heritage is clearly reflected in the daily diet where we find that the names of dishes reflect the daily beliefs and culture of the Chinese people, hence giving names that reflect good fortune and auspicious outcomes that will psychologically promote mental wellbeing of the diners.

Most significantly, the names of New Year dishes reflect the people's prayer for good fortune and an auspicious life. Many Chinese people are always hoping for eternally good fortune, happiness, harmony, 


\section{MALAYSIAN CHINESE NEW YEAR DISHES NOMENCLATURE}

power, wealth and health, especially during grand festivals, prayers or birthday and wedding celebrations. People are encouraged to say good wishes to express their blessings to each other, let alone Chinese New Year.

In traditional Chinese thought and culture, certain words such as 龙 [long] (Dragon) and 凤 [feng] (Phoenix) carry along auspicious meaning. According to previous studies, 龙 [long] (Dragon) and 凤 [feng] (Phoenix) appeared in the name of many dishes. Both of which are the Chinese ancient worship mascots. The totems made by the primitive people showed that humans have a great desire and strong will power to live. People pray for a good future when they face adversity. They believe that these mascots will help them in achieving their aspirations. For example, dragon is the symbol of strength, resolute, wealth, luxury and is a majestic mascot and people believe that the word 龙 [long] (Dragon) will bring blessings to them. Thus, for Chinese people, the Dragon and Phoenix are good combinations to represent the spirit and psychology of the culture of the Chinese people. In this study, 龙 [long] (Dragon) and 凤 [feng] (Phoenix) are found in 凤展鱼唇翅 [feng zhan yu chun chi] ('phoenix shark's lip fin'), 龙凤双鱼炒香饭 [long feng shuang yu chao xiang fan] ('dragon and phoenix dual fish fried rice') as Lu Hua Fang (2007, p.45) asserted that these words will be able to fulfill their believes.

Besides, the Chinese always desire great fortune, wealth and higher job positions; therefore, words like 福 $[f u$ ] (prosperity) and 贵 [gui] (wealth) are often used in Chinese New Year dishes' names such as 富贵年年 [fu gui nian nian] ('wealthy and prestigious year after year'), 富贵延年 [fu gui yan nian] ('wealthy and prestigious prolong life'), 富贵大肥鸡 [ fu gui da fei ji] ('wealthy and prestigious big fat chicken') etc. People also used names like 财源滚进 [cai yuan gun jin] ('profits pouring in from everyway'), 产物如鱼得水 [chan wu ru yu de shui] ('outcome like a stranded fish put back into the water'), 大地黄金 [da di huang jin] ('the golden land'), 穿金戴银 [chuan jin dai yin] ('dripping with gold and silver') etc. for their dishes to show their desire and dedication in achieving great fortune. Others such as 大展鸿图 [da zhan hong $t u$ ] ('great success'), 生意兴隆 [sheng yi xing long] ('thriving and prosperous business'), 风生水起 [feng sheng shui qi] ('prosperity grows like rising wind and water') have also indirectly brought in the meaning of wealth and fortune.

Chinese New Year celebration symbolizes the beginning of a new year. Most dishes are named using words like 四季安康 [si ji an kang] ('four seasons in good health'), 竹报平安 [zhu bao ping an] ('a family letter reporting all is well'), 出入平安 [chu ru ping an] ('safe trip wherever you go') and others, representing peaceful live. From the data collected, there are a total of seven dishes names that portray the message of security and longevity. This shows that Chinese Malaysians have also embraced China's cultural psychology in safety, health, wealth and great fortune.

Chinese Malaysians are found to be still strongly superstitious, in spite of living in this era of advanced scientific technology. They believe that inauspicious words and things are a bad sign that may probably bring disaster to people around them and should therefore be avoided.

In order to connect to the customers and to avoid bringing any undesirable consequences, the chefs need to consider people's thoughts and beliefs when naming the Chinese New Year dishes. However, it is surprising to find that there are a few names that contain inauspicious meanings in the Chinese New Year's menu such as 炒鸡蛋壳盖西红柿 [chao ji dan ke gai xi shi] (scrambled egg with tomato) named as 金屋藏娇 [jin wu cang jiao] ('keep a mistress in a love nest'), 棺材板 [guan cai ban] ('coffin plank') and others. Such dishes are certainly not attractive to customers. 


\section{MALAYSIAN CHINESE NEW YEAR DISHES NOMENCLATURE}

As a summary, Chinese New Year dish naming is clearly aligned to the people's thought and beliefs and their yearning for success, prosperity and wealth. The statement that we can understand ones ethnic culture and thinking through their dishes names is now proven.

\section{Conclusion}

We can conclude that Malaysian dishes nomenclature is very complex and varied whereby the name of a dish can be formed by several kinds of nomenclatures either based on the ingredients used, cultural implication, or a combination of both. Chinese New Year dishes are mainly named by using good values nomenclature, indicating that Chinese people are very particular about what is auspicious during the festival to assure good fortune in the whole New Year.

There are varieties of dishes nomenclatures where people can freely combine them to form a multinomenclature dish name. In Malaysia, most dishes are named using two to thirteen words. These are much longer than China's traditional dishes' names, which normally use just four words as benchmark. Although a longer dish name can describe the content and uniqueness of the dish more precisely, there is a difficulty for the consumers to remember its name. Hence, a signature dish in the Chinese restaurant should not be given a long name. In the dish naming process, some restaurants will incorporate their restaurant's names accordingly into the dish name to emphasize that those particular dishes are the restaurant specialty dishes, served and sold solely by that restaurant.

Malaysia is a multi-cultural country where the cultures of all ethnic groups are somehow influenced by each other. Chinese people have been staying and living with the Malays and Indians for a long period of time. Dishes' names such as 金蓉酥伴千层马来糕 [jin rong su ban qian ceng ma lai gao] ('golden lotus seed paste crisp with mille Malay cake'), 雷沙汤丸伴千层马来糕 [lei sha tang wan ban qian ceng ma lai gao] ('Rasagiline dumpling with mille Malay cake'), 香滑饱仔伴千层马来糕 [xiang hua bao zai ban qian ceng ma lai gao] (creamy mini bun with mille Malay cake) are some examples showing that Malaysian Chinese food and beverage culture has been affected by the local ethnicity. This encourages Malaysian Chinese dishes to become multivariate in terms of culture characteristic and uniqueness as compared to dishes in China. Even though some of the Chinese food and beverages have been influenced and changed by the other ethnic groups, Chinese people still follow and attach firmly to their traditional culture for ensuring an auspicious, lucky, prosperous and peaceful life, in which much are reflected in the local dishes' names. Chinese Malaysians can still claim that they are preserving the traditional and cultural psychology through their dishes nomenclature methods.

From the perspective of dish naming, Chinese Malaysians have a great ability in mastering the Chinese vocabulary in dish naming. In order to attract more customers, the dish naming process should be given more consideration and attention in accordance to the culture and beliefs of consumers.

\section{References}

Ang, L. H. (2015). What's in a name?-A sneak peek into Malaysian Chinese culture through the naming methods of eating houses. Journal of Arts \& Language Studies, 1(1), 1-7

Chen, J. B. (2001). Study on Chinese dishes naming. Cuisine Journal of Yangzhou University, 18(3), $13-17$

Chen, S. H. (2006). The nature and status of the food culture of discipline. Culinary Science Journal of Yangzhou University, 1-36 


\section{MALAYSIAN CHINESE NEW YEAR DISHES NOMENCLATURE}

Deng, Z. F. (2007). Four words dishes and voice inquiry. Journal of Liaoning Administration College, 9(1), 169-170

Gao, R. F. (2007). Chinese dishes named research. The School of Humanities, 1-38

Gong, Y. F. (2009). Metaphor and Chinese dishes name. The Shouthern Journal, (6), 51-56

Guan, M. L. (1997). Emperors' cuisine came. Commercial Culture, 57

Guo, Y. (2008). On catering culture names. Journal of Zhongzhou University, 25(1), 72-75

Jia, M. J., Wang, X. (2009). Nearly three decades of civil food culture research review. Culinary Science Journal of Yang Zhou University, 26(95), 19-23

Lam, K. Q., Ang, L. H. (2014). A Study on the Chinese Names of eating outlets. Southeast Asian Affairs, 157, 78-104

Li, H. L. (2002). "Noun + Noun" formula dishes naming pattern. Journal of Southern Yangtze University, 1(2), 72-74

Lin, G. (1991). Several issues of food culture. Journal of Guangzhou City Polytechnic, (4), 66-70

Lin, N. S. (1994). Ancient Chinese food culture. Taipei: The Commercial press, Ltd.

Liu, F. L. (2005). Art and food culture dishes named. Journal of Guangzhou University, 4 (2), $423-$ 431

Liu, H. Y. (2006). Chinese cuisine in the name of cultural elements analysis and translation. Journal of Huai hua University, 25(6), 116-117

Liu, Z. Q. (2000). Dishes and “Lucky”. Folk Culture, (4), 35

Lu, H. F. (2007). Chinese dishes cover culture. Journal of Taiyuan Teacher College, 6(5), 44-45

Tan, R, W. (2007). Naming art of Chinese cuisine. Rhetoric learning, (2), 32-33

Tong, L. (2002). From the "Source Culture" translation of Chinese dishes. Journal of Hunan Business College, 9(3), 123-124

Wang, C. Y. (2009). Talking about Chinese culture when missing dishes culture and translation strategies. Journal of Xiamen Education College, 11(3), 62-64

Wang, Y. A. (2007). On features of Chinese catering folklore. Journal of Nanning Polytechnic, 12(4), $10-11$

Wei, Q. Z. (2009). On naming dishes. Journal of Nanning Polytechnic. 14(1), 8-11

Wu, Y. J. (2009). Talk about the "Eat" cultural penetration of the Chinese vocabulary. The Science Education Article Collects, 27, 237-238 


\section{MALAYSIAN CHINESE NEW YEAR DISHES NOMENCLATURE}

Xie, Q. (2007). Socio-cultural study of Chinese dish names. Legal System and Society, (7), 747-748

Xiong, X. Y. (1989). The basic of ethnic theories. China: Publishing House of Minority Nationalities

Yao, W. J. (2004). Food culture of the Yang Tze River Basin. Wuhan: Hubei Education Press

Yu, Z.T., Huai, L.H. (2011). Methods and standardization and Chinese dishes named. Journal of Nanning Polytechnic, 6(4), 1-3

Zhang, H. L. (2009). Chinese dishes in the cultural microprobe. Anhui Literature, (5), 364-365

Zhang, S. F. (2005). Chinese food culture. Journal of Zhengzhou Institute of Aeronautical Industry Management, 24(6), 43-45

Zhao, R. G., Xie, D. Y. (2000). Diet introduction of culture. BeiJing: China Light Industry Press

Zhen, S. H. (2005). Names of Chao Zhou dishes cultural connotation. Journal of Guangzhou Polytechnic Normal University (1), 69-73

Zhong, A. N. (2006). On the cultural connotation of Chinese dishes. Academic search for Truth and Reality, (1), 79-80

Zhou, X. (1992). New theory of ethnology. Shaanxi: Shaanxi People's Publishing House

Zhou, Z. M. (2000). Psychology of restaurants and dishes named. Chinese cuisine Culture Study, (1), 34-37

Zhu, X. X. (2002). Chinese dishes elegant and vulgar. Food and life, (2), 60-61

\section{Biodata}

Ng Man Ling is a post-graduate student in the Faculty of Modern Language and Communication, University Putra of Malaysia (UPM), Serdang, Selangor. Currently, she is doing Master of Arts. Address of correspondence: 375, Taman Bunga Raya, Bukit Beruang, 75450, Melaka, Malaysia. Email: moonling_ng@yahoo.com

Ang Lay Hoon (Ph.D) is a senior lecturer at Faculty of Modern Languages, Universiti Putra Malaysia. Her research interests are applied linguistics, Chinese studies and translation. She also conducts Mandarin proficiency course to adult beginners. Address of correspondence: Department of Foreign Languages, Faculty of Modern Languages and Communication, Universiti Putra Malaysia, 43400, Selangor, Malaysia. Email: hlang@upm.edu.my

Lam Kai Chee is a Mandarin proficiency course lecturer in Centre for Language Studies, Universiti Malaysia Sarawak (UNIMAS). His research interests lie in the field of Chinese sociolinguistics and Teaching Mandarin Chinese as a Second/Foreign Language. Address of correspondence: Centre for Language Studies, Universiti Malaysia Sarawak, 94300, Kota Samarahan, Sarawak, Malaysia. Email: kclam@cls.unimas.my 